\title{
ORGANOFILIZAÇÃO DE UMA BENTONITA BRASILEIRA POR DIFERENTES TÉCNICAS E DIFERENTES COMPOSTOS ORGÂNICOS
}

\author{
L. T. VILLAS BOAS ${ }^{1}$, J. L. ALVES ${ }^{1}$, P. T. V. ROSA ${ }^{2}$, A. R. MORALES ${ }^{1}$ \\ ${ }^{1}$ Universidade Estadual de Campinas, Faculdade de Engenharia Química \\ ${ }^{2}$ Universidade Estadual de Campinas, Instituto de Química \\ E-mail para contato: morales@feq.unicamp.br
}

\begin{abstract}
RESUMO - Neste trabalho o estudo comparativo da modificação de uma bentonita com um sal quaternário de amônio e um líquido iônico. Utilizou-se dois métodos de intercalação, dispersão aquosa e semi-sólido. As amostras modificadas foram caracterizadas via difração de raios-X que comprovou a intercalação dos cátions orgânicos, e por análise termogravimétrica para estimar o rendimento reacional da troca catiônica. O meio semi-sólido apresentou a mesma eficiência do meio em dispersão aquosa.
\end{abstract}

\section{INTRODUÇÃO}

Atualmente existe um grande campo de estudos focando argilas como nanocargas para materiais poliméricos, principalmente as bentonitas. Porém existem limitações quanto ao uso desses materiais in natura devido, principalmente, à sua incompatibilidade com os polímeros, pelas suas características hidrofílicas, fazendo-se assim necessária a sua modificação para torná-las organofílicas. A modificação catiônica das argilas encontra espaço para a busca de novos compostos e/ou novos processos que minimizem os aspectos econômicos e ambientais destes materiais. O trabalho de Beall e Goss (2004) mostrou que a síntese de bentonitas organofílicas ou montmorilonitas propriamente ditas é geralmente feita com a técnica de troca de íons. Por esta técnica é feita a modificação da argila com a substituição de cátions trocáveis presentes nas galerias da argila, geralmente $\mathrm{Na}^{+}$que é mais facilmente trocável por ser monovalente, por cátions orgânicos de sais quaternários de amônio (surfactantes catiônicos) ou mesmo outros tipos de sais. A quantidade de intercalante ligado à superfície das lamelas da argila é limitada pela capacidade de troca de cátions da argila (CTC) desta. Segundo Paiva (2009) a preparação de argilas organofílicas pode ser feita no estado sólido-líquido, sólidosólido e sólido-gás. A síntese de argilas organofílicas para nanocompósitos é geralmente realizada por troca de cátions no estado sólido-líquido, em dispersão aquosa e Paiva (2009) propôs, em seu trabalho, a utilização de um método que denominou semi-sólido. Neste contexto, o presente trabalho apresenta um estudo comparativo da modificação de uma bentonita extraída de uma mina localizada no sul da Bahia, com um sal quaternário de amônio e um líquido iônico, utilizando o método convencional, sólido-líquido, em dispersão aquosa e um não convencional, semi-sólido. 


\section{METODOLOGIA}

\subsection{Materiais}

Foi utilizada uma argila bentonítica policatiônica purificada de acordo com Alves (2012), extraída no sul da Bahia com CTC de 90 meq/100 g de argila. Carbonato de sódio anidro foi utilizado na sodificação da argila. Como agentes modificantes foram utilizados um líquido iônico (LI), cloreto de trihexil(tetradecil)fosfônio, adquiro pela Sigma-Aldrich e um sal quaternário de amônio (SQA), cloreto de dioctadecildimetilamônio (Arquad ${ }^{\circledR}$ 2HT-75), também adquirido pela Sigma-Aldrich.

\subsection{Métodos de organofilização}

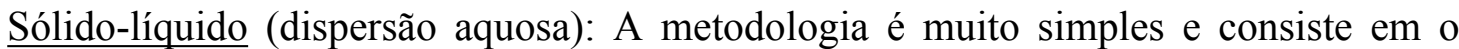
sólido (pó de argila) ser disperso num solvente líquido sob forte agitação para desaglomerar os tactóides de placas de argilominerais e promover a expansão das mesmas. Isto facilita a intercalação do composto orgânico, que normalmente é adicionado na dispersão de argila na forma de solução. A água deionizada ou destilada é o agente mais utilizado devido à sua afinidade com os argilominerais e com a maioria dos compostos de intercalação.

Meio semi-sólido: No estado sólido e "semi-sólido", a argila e o composto orgânico são misturados sem uso ou com pouca quantidade de água. O trabalho de Paiva (2009) mostrou que esse procedimento tem a vantagem de ser um processo ambientalmente correto por não utilizar grandes quantidades de água ou outro solvente e por ser mais fácil e adequado para industrialização. A bentonita seca é misturada diretamente com o surfactante, e depois, é adicionada uma pequena quantidade de água para facilitar a intercalação dos cátions.

\subsection{Preparação das argilas organofílicas}

Sodificação da argila: Esse pré-tratamento das argilas consiste de um processo de ativação usando carbonato de sódio para a troca de cátions interlamelares de $\mathrm{Ca}^{2+}$ por $\mathrm{Na}^{+}$. Segundo Paiva (2009), esse procedimento é geralmente realizado, pois o íon $\mathrm{Na}^{+}$hidrata-se mais que o $\mathrm{Ca}^{2+}$, o que leva a maiores valores de distância interlamelar nas bentonitas.

Reação em dispersão aquosa: $1,5 \mathrm{~g}$ de argila seca foram dispersos em água, numa proporção de $5 \%$ em massa de argila em água, por $20 \mathrm{~min}$. O agente modificante (100 e 150\% da CTC) foi solubilizado em $2 \mathrm{~mL}$ de etanol, e adicionado aos poucos à dispersão. A temperatura do meio reacional foi aferida e mantida em $80^{\circ} \mathrm{C}$ por $1 \mathrm{~h}$. A argila organofílica resultante foi filtrada, e lavada com uma solução 1:1 em volume de água deionizada e etanol. As amostras foram secas em estufa a $60^{\circ} \mathrm{C}$ por $24 \mathrm{~h}$, moídas e passadas em peneira ABNT de $200 \operatorname{mesh}(<74 \mu \mathrm{m})$.

Meio semi-sólido: A reação foi realizada em um almofariz com pistilo de ágata, no qual 1,5g de argila seca foram diretamente misturados com o composto orgânico (100 e 150\% da CTC) por 10 min, obtendo-se um material visualmente homogêneo. Em seguida, foram adicionados 1,6 g (dispersão de 95\% em massa de argila em água) de água destilada, e 
misturados por mais 10 min. Posteriormente, a mistura foi deixada em repouso por $1 \mathrm{~h}$, seguido das mesmas etapas do procedimento anterior de lavagem, secagem e desaglomeração.

As amostras foram nomeadas de acordo com o pré tratamento de sodificação: $\mathrm{BO}$ bentonita organofílica; BSO - bentonita sódica organofílica. Desta forma as seguintes nomenclaturas foram atribuídas às argilas organofílicas: $\mathrm{BO} / \mathrm{BSO}-\mathrm{XY}-\mathrm{Z}$, onde $\mathrm{X}$ é o tipo de composto orgânico - SQA ou LI; Y é a quantidade do composto em relação à CTC da argila $100(100 \%)$ ou 150 (150\%); Z é o método utilizado na modificação - DA (dispersão aquosa) ou SS (semi-sólido).

\subsection{Caracterização}

Para avaliar o grau de intercalação do agente modificante na argila, análises de difração de raios-X (DRX) foram conduzidas em equipamento SHIMADZU XRD-7000, com varredura na faixa de $1,5^{\circ}$ a $10^{\circ}(2 \theta)$, radiação de $\mathrm{K} \alpha$ do $\mathrm{Cu}(\lambda=1,54)$, tensão de $40 \mathrm{kV}$ e corrente $30 \mathrm{~mA}$. As amostras foram analisadas quanto à degradação térmica por termogravimétrica (TGA) em equipamento TA Instruments, modelo SDT 2960, em atmosfera inerte de gás nitrogênio sob fluxo laminar fixo de $50 \mathrm{ml} / \mathrm{min}$, taxa de aquecimento de 10 ${ }^{\circ} \mathrm{C} / \mathrm{min}$, de 40 até $700^{\circ} \mathrm{C}$ (estabilização em $40^{\circ} \mathrm{C}$ por $15 \mathrm{~min}$ ), com aproximadamente $10 \mathrm{mg}$ de amostra, em cadinhos de alumina.

\section{RESULTADOS}

Os difratogramas obtidos por DRX são apresentados na Figura 1. Observa-se que houve a intercalação dos cátions orgânicos nas galerias dos argilominerais em todas as amostras funcionalizadas. Ocorreu o alargamento do espaçamento basal $\left(\mathrm{d}_{001}\right)$ de $1,56 \mathrm{~nm}$ da argila purificada para cerca de 3,5 nm para as argilas com SQA acordando com os resultados obtidos por Sarkar et al. (2011), e cerca de 2,5 nm com LI que está de acordo com o trabalho de Naveau et al. (2009). Analisando-se a Figura 1a, referente às amostras modificadas com SQA, percebe-se que houve um ligeiro aumento no valor do $\mathrm{d}_{001}$ do argilomineral com o aumento da quantidade de composto orgânico em relação à CTC da argila. Os valores passaram de 3,06 para 3,77 nm entre BO-SQA100-DA e BO-SQA150-DA, e de 3,48 para 3,81 nm entre BO-SQA100-SS e BO-SQA150-SS. Esse incremento pode ser atribuído a uma maior quantidade de cátion orgânico intercalado. Comparando-se os métodos, observa-se um pequeno incremento para as amostras modificadas em semi-sólido, de 3,06 para 3,48 nm nas amostras com $100 \%$ de SQA, e de 3,77 para 3,81 nm com 150\% de SQA. Esse resultado pode ser um indício de que a técnica alternativa em meio semi-sólido foi melhor do que a convencional em dispersão aquosa na intercalação dos cátions orgânicos entre as camadas do argilomineral. As amostras organofilizadas com a argila sodificada apresentaram um pequeno incremento quando comparadas com a mesma amostra sem o pré-tratamento, de 3,77 para 3,79 nm entre BO-SQA150-DA E BSO-SQA150-DA, e de 3,81 para 3,92 nm entre BOSQA150-SS E BSO-SQA150-SS.

A Figura 1b mostra os resultados de DRX das amostras funcionalizadas com o líquido iônico. De modo geral, percebe-se que não houve uma influência significativa no valor do espaçamento basal ao variar a quantidade do composto. Porém as amostras sem o tratamento prévio de sodificação e organofilizadas em meio semi-sólido apresentaram um valor de $\mathrm{d}_{001}$ significativamente inferior às amostras correspondentes em dispersão aquosa, de 2,52 nm em 
BO-LI100-SS e 2,40 nm em BO-LI150-SS. Essa diferença não foi significativa entre as amostras $\mathrm{BSO}$, indicando que a sodificação das amostras melhorou o mecanismo de intercalação dos cátions orgânicos deste composto.

Figura 1 - Difratogramas de raios X: a) argilas modificadas com o sal quaternário de amônio; b) argilas modificadas com o líquido iônico.

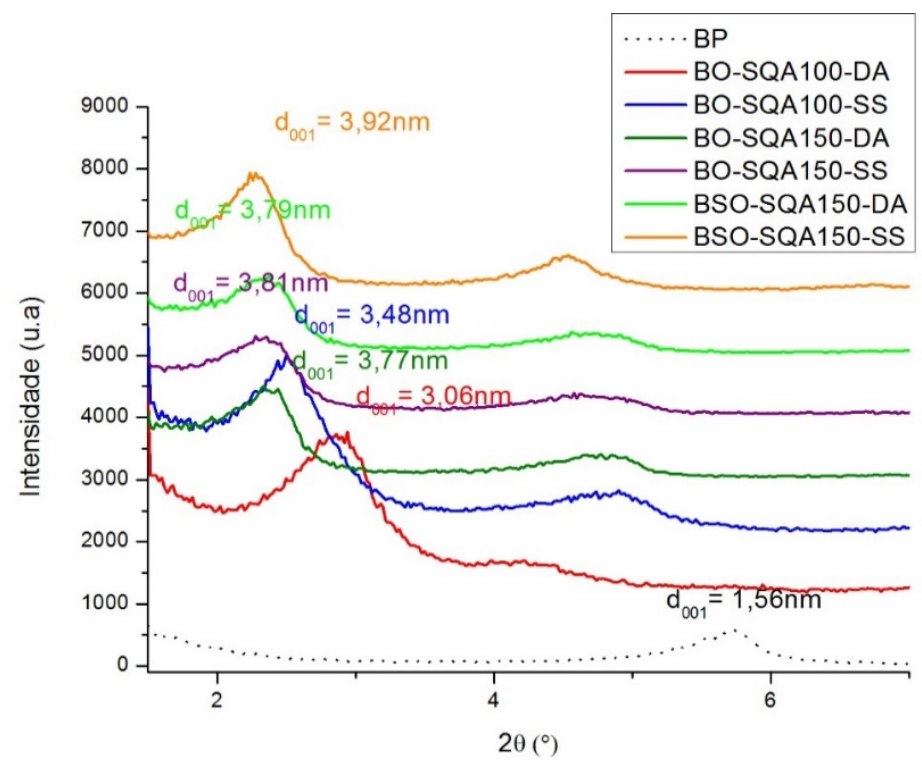

a)

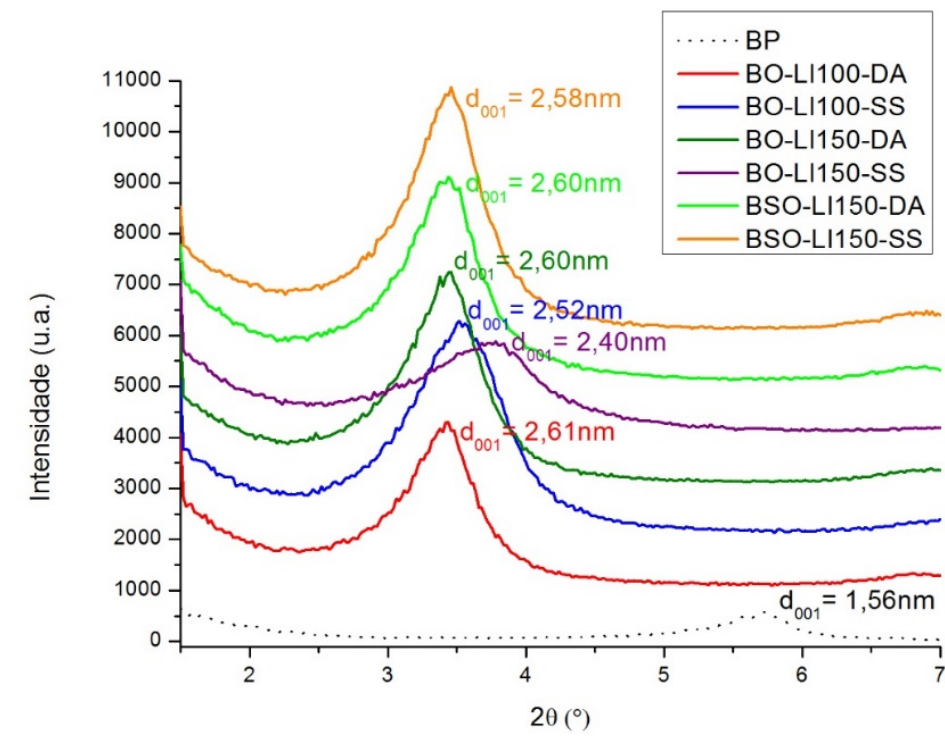

b)

A Figura 2 e Tabela 1 apresentam os resultados de perda de massa das amostras obtidas pela TGA. As amostras modificadas com o mesmo composto apresentam mesma tendência de perda de massa. O LI mostrou-se mais estável em aproximadamente $100^{\circ} \mathrm{C}$ em 
relação ao SQA, que é um fator de suma importância na obtenção de nanocompósitos, que exige elevadas temperaturas de processamento. Ao compara-se os dois métodos aplicados, percebe-se que não houve diferença significativa na eficiência. A sodificação foi relativamente pouco significativo no rendimento na funcionalização com o composto SQA e não significativo com o LI.

Figura 2 -Análises termogravimétricas: a) argilas modificadas com o sal quaternário de amônio (SQA); b) argilas modificadas com o líquido iônico (LI).

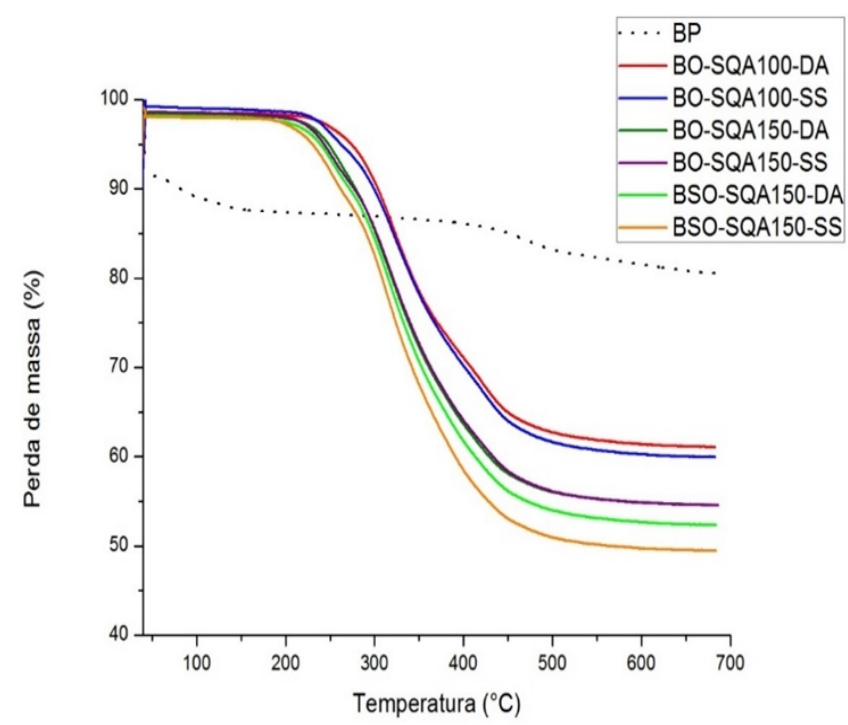

a)

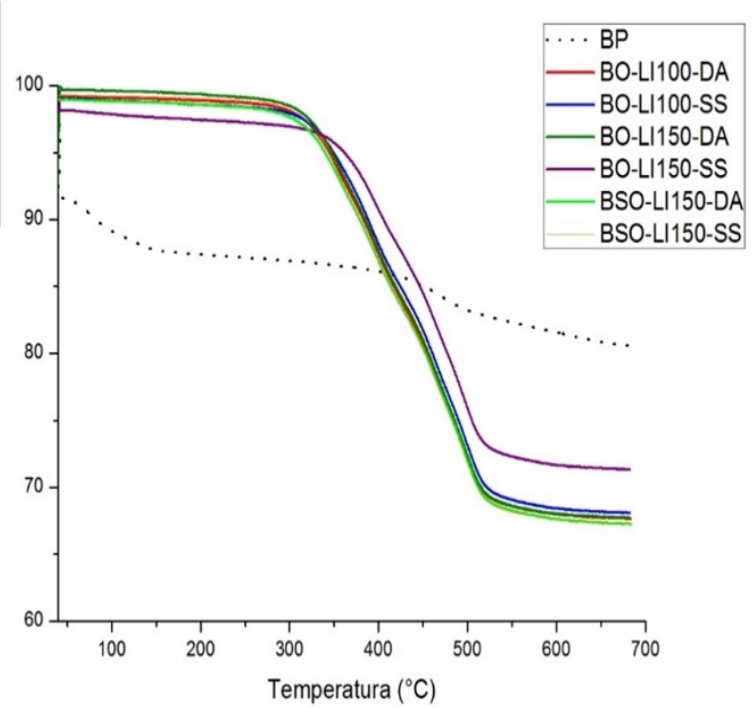

b)

Tabela 1 - Dados obtidos pela TGA das amostras.

\begin{tabular}{cccccc}
\hline Amostra & $\mathrm{T}_{\text {onset }}\left({ }^{\circ} \mathrm{C}\right)$ & $\begin{array}{c}\text { Matéria } \\
\text { orgânica } \\
\text { intercalada (\%) }\end{array}$ & Amostra & $\mathrm{T}_{\text {onset }}\left({ }^{\circ} \mathrm{C}\right)$ & $\begin{array}{c}\text { Matéria } \\
\text { orgânica } \\
\text { intercalada (\%) }\end{array}$ \\
\hline BO-SQA100-DA & 205 & 28,7 & BO-LI100-DA & 290 & 17,8 \\
BO-SQA100-SS & 204 & 27,9 & BO-LI100-SS & 293 & 18,7 \\
BO-SQA150-DA & 194 & 29,9 & BO-LI150-DA & 296 & 18,1 \\
BO-SQA150-SS & 190 & 29,7 & BO-LI150-SS & 295 & 16,6 \\
BSO-SQA150-DA & 190 & 30,6 & BSO-LI150- & 275 & 16,8 \\
BSO-SQA150-SS & 186 & 31,9 & BSO-LI150-SS & 282 & 16,9 \\
\hline
\end{tabular}

\section{CONCLUSÃO}

De acordo com os resultados, pode-se concluir que o argilomineral estudado foi modificado com a utilização de ambos compostos orgânicos e que o método semi-sólido 
mostrou tão eficiente quanto ao método convencional de organofilização em dispersão aquosa. Destaca-se a maior estabilidade térmica obtida pela funcionalização com o LI. O pré tratamento de sodificação da amostra não mostrou influência muito significativa no processo de modificação, podendo este ser eliminado do processo, já que trata-se de uma etapa de alto custo, tempo e impacto ambiental.

\section{AGRADECIMENTOS}

Os autores agradecem ao $\mathrm{CNPq}$ e ao programa PIBIC pelo apoio financeiro, e ao grupo de pesquisa PROTEC-UFBA pelo fornecimento da argila bentonítica.

\section{REFERÊNCIAS}

ALVES, J. L. Estudo e Desenvolvimento de uma Proposta Industrial para selecionar e Purificar Argilas Bentoníticas Baseada na Lei de Stokes. Departamento de Engenharia Química da Universidade Federal da Bahia, Salvador-BA. Dissertação (Mestrado em Engenharia Industrial), 2012.

BEALL G. W.; GOSS M. Self-assembly of organic molecules on montmorillonite, Applied Clay Science, v. 27, p.179, 2004

LIVI, S.; DUCHET-RUMEAU, J.; PHAM, T. N.; GÉRARD, J. F. A comparative study on different ionic liquids used as surfactants: Effect on thermal and mechanical properties of high-density polyethylene nanocomposites. Journal of colloid and interface science, v. 349, n. 1, p. 424-33, 2010.

NAVEAU, E.; CALBERG, C.; DETREMBlEUR, C.; BOURBIGOT, S.; JÉRÔME, C. ALEXANDRE, M. Supercritical $\mathrm{CO} 2$ as an efficient medium for layered silicate Organomodification: Preparation of thermally stable organoclays and dispersion in polyamide 6. Polymer, v. 50, n. 6, p. 1438-1446, 2009.

PAIVA, L.B.;Estudo do potencial de bentonitas nacionais e argentinas na obtenção de bentonitas organofílicas em dispersão aquosa e meio semi-sólido visando à aplicação em nanocompósitos poliméricos. Faculdade de Engenharia Química, Campinas-SP. Tese, 2009

SARKAR, B.; MEGHARAJ, M.; XI, Y.; NAIDU, R. Structural characterisation of Arquad® 2HT-75 organobentonites: surface charge characteristics and environmental application. Journal of hazardous materials, v. 195, p. 155-61, 2011. 